\title{
RNA-binding motif protein 5 negatively regulates the activity of Wnt/ß-catenin signaling in cigarette smoke-induced alveolar epithelial injury
}

\author{
YU-QIU HAO ${ }^{1}$, ZHEN-ZHONG SU ${ }^{1}$, XUE-JIAO LV ${ }^{1}$, PING LI $^{2}$, PENG GAO ${ }^{1}$, \\ CHEN WANG $^{1}$, YUE BAI ${ }^{1}$ and JIE ZHANG ${ }^{1}$ \\ Departments of ${ }^{1}$ Respiratory Medicine and ${ }^{2}$ Paediatrics, The Second Affiliated Hospital \\ of Jilin University, Chuangchun, Jilin 130041, P.R. China
}

Received December 17, 2014; Accepted February 17, 2015

DOI: $10.3892 /$ or.2015.3828

\begin{abstract}
Cigarette smoking is closely associated with various respiratory diseases. Oxidants and carcinogens in cigarettes are reported to induce various airway epithelial injuries. However, the underlying mechanisms remain unclear. The aims of the present study were to determine the involvement of RNA-binding motif protein 5 (RBM5) and Wnt/ $\beta$-catenin signaling in cigarette smoke-induced alveolar epithelial injury, as well as the interaction between both. A549 cells were treated with cigarette smoke extract (CSE). The MTT assay was used to assess the effects of CSE on cell viability. The levels of RBM5 and $\mathrm{Wnt} / \beta$-catenin/GSK3$\beta$ were detected by semi-quantitative reverse transcription-polymerase chain reaction (RT-PCR) and western blot analysis. A luciferase assay was used to assess the activity of $\beta$-catenin/T-cell factor (TCF) signaling. The results revealed that CSE inhibited A549 cell viability in both a dose- and time-dependent manner. Cytosolic and nuclear $\beta$-catenin levels were significantly increased following CSE treatment, compared with those in the control cells $(\mathrm{P}<0.05)$. The luciferase activity in CSE-exposed cells transfected with the TCF luciferase reporter wild-type plasmid (pGL3-OT) was significantly greater than that in cells without CSE exposure $(33,167 \pm 3,085$ vs. $19,978 \pm 1,916$, respectively, $\mathrm{P}<0.05)$. Both the mRNA and protein levels of RBM5 in the CSE-treated cells were significantly reduced compared to the levels in the controls (all $\mathrm{P}<0.05$ ). The overexpression of RBM5 inhibited Wnt/ $\beta$-catenin signaling in the A549 cells, while silencing of RBM5 enhanced Wnt/ $\beta$-catenin signaling. The $\beta$-catenin/TCF signaling inhibitor ICG-001 had no apparent effect on the RBM5 levels. Downregulation of RBM5 and activation of Wnt/ $\beta$-catenin signaling are involved in CSE-induced alveolar
\end{abstract}

Correspondence to: Dr Jie Zhang, Department of Respiratory Medicine, The Second Affiliated Hospital of Jilin University, Chuangchun, Jilin 130041, P.R. China

E-mail: doctorzhangj@sina.com

Key words: RNA-binding motif protein 5, $\beta$-catenin, cigarette smoking, lung injury epithelial injury. RBM5 acts as an upstream molecule that negatively regulates the activity of Wnt/ $\beta$-catenin signaling.

\section{Introduction}

Cigarette smoking is closely associated with the development and progression of various respiratory diseases including lung cancer, chronic obstructive pulmonary disease (COPD), interstitial lung diseases and bronchial asthma $(1,2)$. In particular, lung cancer and COPD are the main causes of death related to cigarette smoking in the world. Particles in cigarette smoke are reported to induce various lung injuries including inflammation and fibrosis $(3,4)$.

Studies have shown that $\mathrm{Wnt} / \beta$-catenin/T-cell factor (TCF) signaling is activated during lung injury and promotes the survival and migration of alveolar epithelial cells (5). $\beta$-catenin is a key player of canonical Wnt signaling. The activation of this signaling pathway mainly depends on the cytoplasmic accumulation and nuclear localization of $\beta$-catenin $(6,7)$. First, a Wnt ligand binds to a seven-pass transmembrane Frizzled (Fz) receptor as well as its coreceptor LRP6 or LRP5 (8). The binding leads to depolymerization of glycogen synthase kinase-3 $\beta$ (GSK-3 $\beta$ )/APC/Axin complexes in the cytoplasm, $\beta$-catenin release and phosphorylation. It results in the accumulation and stabilization of cytosolic $\beta$-catenin, which then travels to nuclei to form complexes with members of the DNA-binding family TCF-1/lymphoid enhancer factors (LEF-1, 3 and 4). Activation of $\beta$-catenin/TCF signaling promotes the downstream target gene transcription involved in cell proliferation, migration and differentiation. These targets include cyclin D1, c-Myc and matrix metalloproteinases (MMP-2, -3, -7, -9 and -13) (9).

RNA-binding motif protein 5 (RBM5, previously referred to as g15, LUCA-15 or H37) is one of $\sim 35$ genes located in the 370-kb tumor suppressor locus on chromosome 3p21.3 (10). RBM5 is reported to induce cell cycle arrest and apoptosis by pre-mRNA alternative gene splicing $(11,12)$. It is also suggested to act as a tumor-suppressor gene by inhibiting tumor growth and reducing metastatic potential $(11,12)$. Both the mRNA and protein levels of RBM5 are significantly lower in nonsmall cell lung carcinomas (NSCLCs) than those in normal 
tissues (13). The RBM5 level is negatively correlated with the smoking status in patients with lung cancer (12). In addition to lung cancer, whether the RBM5 level is also reduced in other cigarette smoke-induced lung injury has not been determined. Meanwhile, the activation of the Wnt/ $\beta$-catenin signaling pathway plays an important role in diseases associated with cigarette smoking $(5,14,15)$. Alveolar epithelial cells are the major components of the airway epithelium that are directly affected by cigarette smoking. The molecular mechanisms by which the $\mathrm{Wnt} / \beta$-catenin signaling pathway is activated during cigarette smoke-induced lung injury remains unclear. Whether RBM5 is involved in the activation of $\mathrm{Wnt} / \beta$-catenin signaling during lung injury also remains unknown.

The aims of the present study were to determine the level of RBM5 in cigarette smoke-injured lung epithelium and the involvement of RBM5 in the activation of $\mathrm{Wnt} / \beta$-catenin signaling during lung injury. A549 cells were treated with cigarette smoke extract (CSE) at a series of concentrations and for various times. The present study demonstrated that the level of RBM5 in cigarette smoke-injured lung epithelium was significantly reduced and that RBM5 acts as an upstream molecular regulator of $\mathrm{Wnt} / \beta$-catenin signaling activity during lung injury.

\section{Materials and methods}

Preparation of CSE. CSE was prepared using a popular type of cigarette in China (Hong Shuang Xi, $12 \mathrm{mg}$ of tar, $1.1 \mathrm{mg}$ of nicotine), as previously described (16). Briefly, a syringedriven apparatus device was designed and operated to allow a stream of smoke to flow into a tube-shaped trap, which was maintained at room temperature. The smoke then entered a 1.5-liter flask submerged in liquid nitrogen. The amount of smoke obtained was determined by the increase in the weight inside the flask. The collected smoke particles were dissolved in dimethyl sulfoxide (DMSO) at $40 \mathrm{mg} / \mathrm{ml}$, and the solution was sterile-filtered through a $0.22-\mu \mathrm{m}$ syringe filter (Millipore, Watford, UK). The CSE solution was prepared by dissolving the condensate in DMSO, which was then stored in small vials at $-80^{\circ} \mathrm{C}$.

Cell culture. The human alveolar epithelial cell line A549 was obtained from Jilin University. The cells were cultured in RPMI-1640 supplemented with $10 \%$ fetal bovine serum (FBS; Gibco Waltham, MA, USA) and antibiotics (100 IU/ml penicillin and $100 \mu \mathrm{g} / \mathrm{ml}$ streptomycin) at $37^{\circ} \mathrm{C}$ in $5 \% \mathrm{CO}_{2}$.

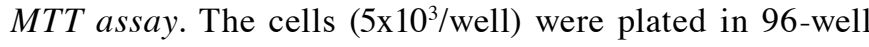
microtiter plates. After $24 \mathrm{~h}$ of culture in regular medium, the cells were then cultured in serum-free medium either supplemented with CSE $(5,10,15,20,40,60,80$ and $160 \mu \mathrm{g} / \mathrm{ml}$, respectively) or DMSO for $6,12,24,48$ and $72 \mathrm{~h}$, respectively. Next, $10 \mu \mathrm{l}$ of 3-(4,5-dimethylthiazol-2yl-)-2,5-diphenyltetrazolium bromide (MTT) (Sigma-Aldrich, St. Louis, MO, USA) (stock concentration: $5 \mathrm{mg} / \mathrm{ml}$ in phosphate-buffered saline; PBS) was added to each well. After incubation for $4 \mathrm{~h}$ with MTT, $150 \mu \mathrm{l}$ of DMSO was added. The plate was agitated for $10 \mathrm{~min}$, and the optical density (OD) value was measured at $570 \mathrm{~nm}$ using a $\mathrm{V}_{\max }$ Microplate Reader (Molecular Devices, Sunnyvale, CA, USA). Background control wells containing the same volume of complete culture medium were included in each assay, and the background was subtracted before data analysis.

Semi-quantitative reverse transcription-polymerase chain reaction $(R T-P C R)$. Cellular total RNA was isolated using TRIzol reagent (Takara Biotechnology Co., Dalian, China), according to the manufacturer's instructions. cDNA was reverse transcribed using a reverse transcription kit (Takara Biotechnology), according to the manufacturer's instructions. Semi-quantitative real-time PCR was then performed using the following primers: RBM5, forward, 5'-ACACGATGGAT GGAAGCCA-3' and reverse, 5'-TCTGCTCTGCCTCTGAC TT-3'; glyceraldehyde-3-phosphate dehydrogenase (GAPDH), forward, 5'-GGGTGATGCTGGTGCTGAGTATGT-3' and reverse, 5'-AAGAATGGGAGTTGCTGTTGAAGTC-3'. The primer oligonucleotides were synthesized by Shanghai Promega Biological Products, Ltd. (Shanghai, China). For each set of PCRs, $5 \mu \mathrm{l}$ of reverse-transcribed RNA (cDNA) was added directly into a PCR mixture (final volume of $50 \mu \mathrm{l}$ ) containing 1X Taq DNA polymerase reaction buffer (Shanghai Promega Biological Products), $2.5 \mathrm{mM} \mathrm{MgCl}_{2}, 0.2 \mathrm{mM}$ dNTP mixture, 1 unit of Taq DNA polymerase (Takara Biotechnology), and $1 \mu \mathrm{M}$ of the appropriate primer pair. The resulting amplified DNA fragments were separated by electrophoresis through a $1.5 \%$ agarose gel, and the resulting bands were visualized and scanned using a white ultraviolet transilluminator (UltraViolet Products Ltd., Cambridge, UK) and quantified by densitometry.

Immunofluorescence staining. The cells were fixed with cold $100 \%$ methanol at $-20^{\circ} \mathrm{C}$ for $5 \mathrm{~min}$ and permeabilized with PBS-0.5\% Triton X-100 for 5 min. After blocking with 5\% bovine serum albumin for $1 \mathrm{~h}$ at $37^{\circ} \mathrm{C}$, the cultures were incubated with rabbit polyclonal anti- $\beta$-catenin antibody $(1: 150$ dilution) overnight at $4^{\circ} \mathrm{C}$. After washing, the cells were incubated with $\mathrm{Cy} 3$-conjugated goat anti-rabbit secondary antibody (1:200 dilution) for $1 \mathrm{~h}$ at room temperature. Finally, DAPI (Sigma-Aldrich) was used to stain the nuclei. Fluorescence images were captured using a fluorescence microscope (Nikon Eclipse E600; Nikon, Tokyo, Japan).

Western blot analysis. The cells were plated in culture dishes for $24 \mathrm{~h}$ in RPMI-1640 and 10\% FBS before exposure to CSE. The supernatant of the cultured cells was discarded, and the attached cells were washed twice with PBS. The cells were incubated with CSE $(0,10,20,40$ and $80 \mu \mathrm{g} / \mathrm{ml}$, respectively) or DMSO for $48 \mathrm{~h}$. After the treatments, for the preparation of crude cell lysates, the cells were harvested in accordance with the treatment routines described above, washed with cold PBS, and then incubated in ice-cold radioimmunoprecipitation assay buffer. The cells were sonicated on ice for $30 \mathrm{sec}$ and lysed at $4^{\circ} \mathrm{C}$ for $60 \mathrm{~min}$. The cell lysates were then centrifuged for $30 \mathrm{~min}$ at $12,000 \mathrm{x} \mathrm{g}$ and $4^{\circ} \mathrm{C}$. For cell fractionation into the cytoplasmic and nuclear extracts, the Cytoplasmic Extraction kit (CWBIO, Beijing, China) was used according to the manufacturer's instructions. The protein concentrations were determined using a protein assay kit (Bio-Rad Laboratories, Hercules, CA, USA). Equal amounts of lysates $(40 \mu \mathrm{g})$ were separated using $12 \%$ SDS-PAGE and transferred onto nitro- 

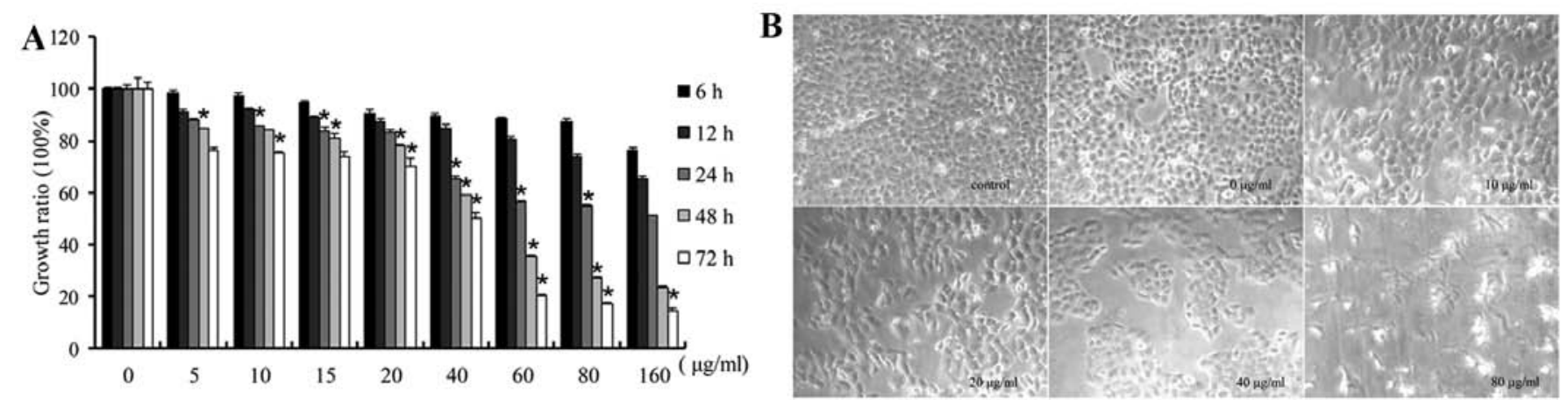

Figure 1. Effects of cigarette smoke extract (CSE) on cell viability in vitro. A549 cells were treated with various concentrations (as indicated) of CSE for 6, $12,24,48$ and $72 \mathrm{~h}$, respectively. (A) The cytotoxicity of CSE on cell growth (\%) was determined by an MTT assay. Data were collected from three individual experiments, and each was performed in triplicate. ${ }^{*} \mathrm{P}<0.05$ compared with the DMSO-treated control group. (B) Representative morphological changes of cells following CSE treatments. A549 cells were treated with DMSO or various concentrations of CSE for 48 h. The images were captured under a phasecontrast light microscope (magnification, $\mathrm{x} 200$ ).

cellulose membranes (Millipore, Bedford, MA, USA). The membranes were blocked with $5 \%$ non-fat milk diluted in buffer $(10 \mathrm{mM}$ Tris- $\mathrm{HCl}, 100 \mathrm{mM} \mathrm{NaCl}$ and $0.1 \%$ Tween20) for $1 \mathrm{~h}$ at room temperature. The membranes were then probed with antibodies including anti-RBM5 (ab85504), anti- $\beta$-catenin (E247, ab32572), anti-His-H3 (acetyl K27, ab4729), anti-p- $\beta$-catenin and (phospho-Y654, ab24925) and anti- $\beta$-actin [ACTN05 (C4), ab3280] from Abcam (Cambridge, MA, USA), anti-Wnt-2 (11160-1-AP), anti-Wnt7a (10605-1-AP), anti-FRZB (12884-1-AP), anti-p-GSK-3 $\beta$ (phospho-Y216, ab75745) and anti-GSK-3 $\beta$ from Proteintech Group, Inc. (Chicago, IL, USA; 22104-1-AP), overnight at $4^{\circ} \mathrm{C}$. Horseradish peroxidase-conjugated secondary antibodies (Santa Cruz Biotechnology) at a dilution of 1:500 were then added to the solution and allowed to incubate for $1 \mathrm{~h}$ at room temperature. The protein bands were then detected using an Enhanced Chemiluminescence kit (Pierce Biotechnology Ltd., Rockford, IL, USA). The protein levels were quantified by densitometry using Quantity One software (Bio-Rad Laboratories).

Luciferase assay. The cells were plated onto a 12-well plate 1 day prior to transfection. Following confirmation of $70-80 \%$ confluency, the cells were transfected with $0.4 \mu \mathrm{g}$ of TCF luciferase reporter plasmids (wild-type, pGL3-OT; mutant, pGL3-OF, respectively) for $24 \mathrm{~h}$. Meanwhile, the cells in each group were cotransfected with $0.1 \mu \mathrm{g}$ of $\beta$-galactosidase expression vector ( $\mathrm{pCH} 110)$ to normalize the transfection efficiency. The cells were then treated with $40 \mu \mathrm{g} / \mathrm{ml} \mathrm{CSE}$ and incubated for $48 \mathrm{~h}$. Finally, the luciferase reporter assay and $\beta$-galactosidase assay were performed using commercial kits as directed by the manufacturer. The luciferase activity was read using a Lumat LB 9507 luminometer (EG\&G Berthold, Bad Wildbad, Germany) and normalized for $\beta$-galactosidase activity (OD420).

Overexpression of RBM5 in the cells. The cells (4x105/well) were plated onto a 6 -well plate and were transfected with $4 \mu \mathrm{g}$ of DNA from the expression vector pcDNA3 or pcDNA3-RBM5 using Lipofectamine 2000 (Life Technologies, Carlsbad, CA, USA). After transfection for $6 \mathrm{~h}$, the cell culture medium was replaced with fresh medium. The cells were harvested at $48 \mathrm{~h}$ following transfection.

The pcDNA3.1 and pcDNA3.1-RBM5 plasmids were provided by Dr Leslie Sutherland (Research Program, Northeast Cancer Centre, Health Sciences North, Toronto, ON, Canada). CONO77-shRBM5 was provided by Shanghai Genechem Co., Ltd. (Shanghai, China).

Silencing of RBM5 in the cells. A short hairpin RNA (shRNA) sequence targeting human RBM5 and a non-target sequence were obtained from Shanghai Genechem. The RBM5 siRNA sequences used were forward, 5'-CCACCAAAGAUGGCAU UGATT-3' and reverse, 5'-UCAAUGCCAUCUUUGGUGG TT-3'; and those of the non-target shRNA (Scramble) were forward, 5'-UUCUCCGAACGUGUCACGUTT-3' and reverse, 5'-ACGUGACACGUUCGGAGAATT-3'. The transfections with siRNA were performed using Lipofectamine 2000 according to the manufacturer's protocol. Briefly, the A549 cells were seeded into 6-well plates and transfected the next day with 100 pmol of shRBM5 or shScramble using $10 \mu \mathrm{l}$ of Lipofectamine 2000. The cells were harvested $48 \mathrm{~h}$ after transfection.

Treatment of the cells with the $\beta$-catenin/TCF inhibitor. The novel small-molecule ICG-001 (S2662; Selleckchem, Houston, TX, USA) which selectively inhibits $\beta$-catenin/TCF-mediated gene transcription, was previously described $(23,25)$. A549 cells were seeded onto 6-well plates and treated with $12.5 \mu 1$ of ICG-001 or DMSO on the second day. After treatment for $24 \mathrm{~h}$, the cell culture medium was replaced with medium containing the same dose of ICG-001 or DMSO. The cells were continuously incubated for another $24 \mathrm{~h}$. Then, the protein was extracted from the cells and subjected to western blot analysis.

\section{Results}

Cytotoxicity of CSE on cell viability and growth. The effects of CSE on cell growth in vitro were evaluated using an MTT assay. A549 cells were treated with different concentrations of CSE $(5,1015,20,40,80$ and $160 \mu \mathrm{g} / \mathrm{ml}$, respectively) for $6,12,24,48$ or $72 \mathrm{~h}$, respectively. The results showed that 
A

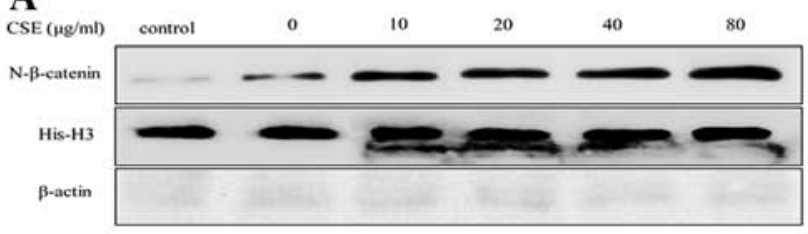

B

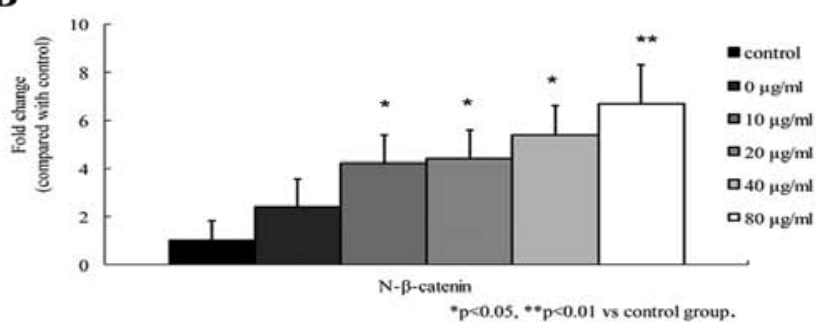

C

D
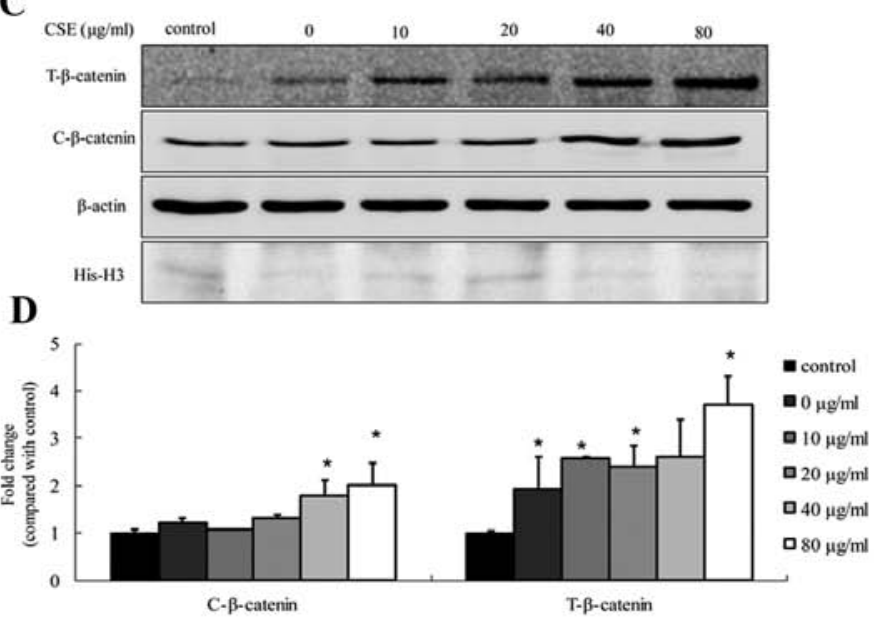

Figure 2. Upregulation of $\beta$-catenin in the A549 cells following CSE treatments. (A and B) The cells were treated with different concentrations of CSE or DMSO for $48 \mathrm{~h}$. The cell lysates were extracted from the cells and were subjected to western blot analysis using anti- $\beta$-catenin, anti-actin and anti-His-H3 antibodies, respectively. Representative western blot images of nuclear N- $\beta$-catenin (A) as well as cytosolic C- $\beta$-catenin and total T- $\beta$-catenin (C), and quantification of nuclear $\mathrm{N}-\beta$-catenin levels relative to control (B) and cytosolic C- $\beta$-catenin levels relative to the control (D) are shown. All data are expressed as mean \pm standard deviation from three replicate experiments. ${ }^{*} \mathrm{P}<0.05,{ }^{* *} \mathrm{P}<0.01$.
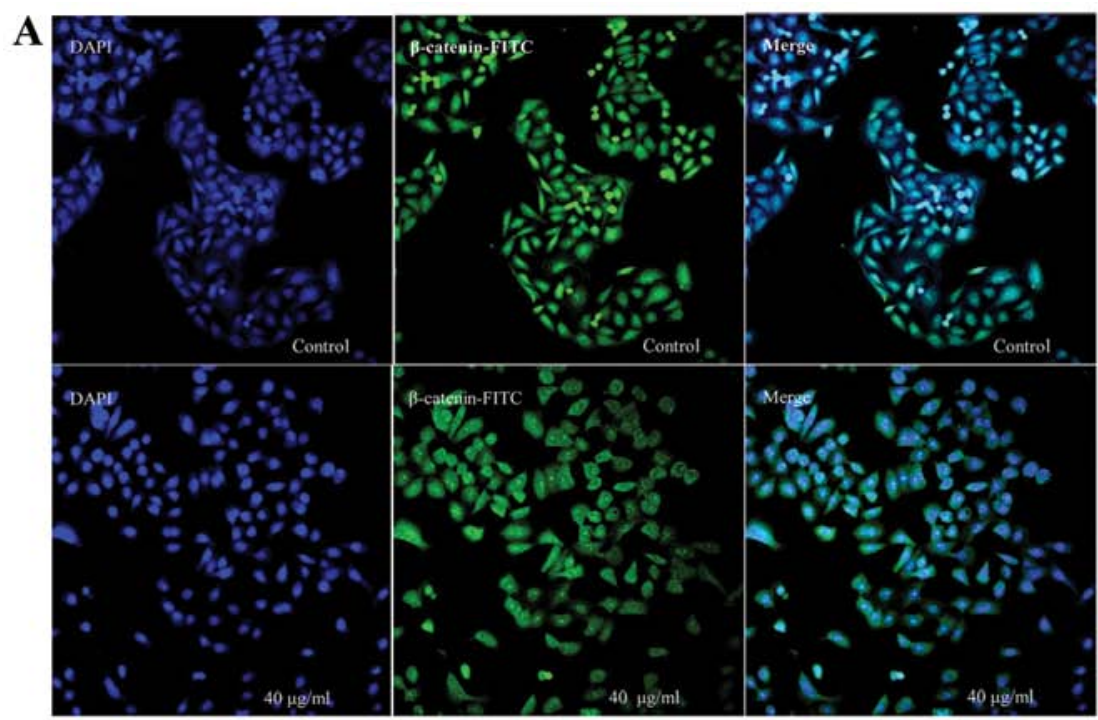

B

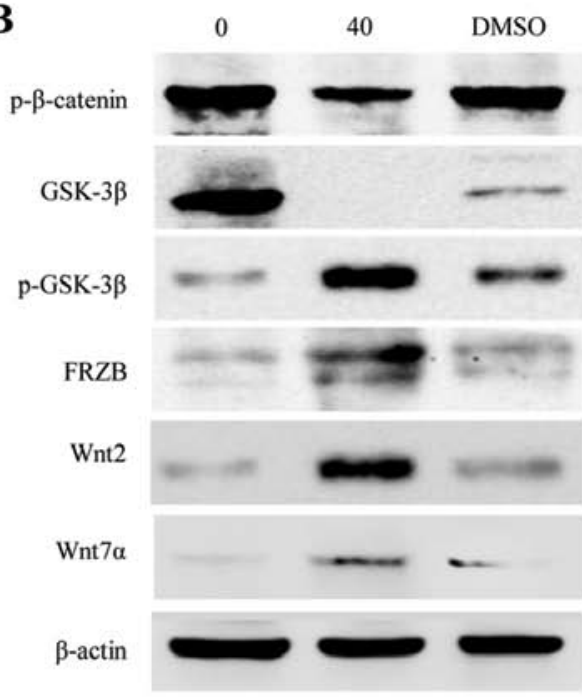

Figure 3. $\beta$-catenin protein expression in the A549 cells following CSE treatments. (A) The cells were treated with $40 \mu \mathrm{g} / \mathrm{ml}$ of CSE or DMSO for $48 \mathrm{~h}$. Immunostaining of the cells with the anti- $\beta$-catenin antibody (green). The nuclei of cells were stained with DAPI (blue). (B) The cells were treated with 0 or $40 \mu \mathrm{g} / \mathrm{ml}$ CSE or DMSO for $48 \mathrm{~h}$. Whole cell lysates were extracted, and western blots were performed as described in Materials and methods.

CSE exposure inhibited cell growth and viability (Fig. 1A). Compared with the DMSO-treated control cells, which were closely adherent, the CSE-exposed cells showed delayed confluence and larger interspaces between the cells under light micro-scopy. The shrinkage and death of cells were more apparent after exposure to $80 \mu \mathrm{g} / \mathrm{ml} \mathrm{CSE}$ for $48 \mathrm{~h}$ (Fig. 1B).

Increased cytoplasmic accumulation and nuclear translocation of $\beta$-catenin in the $A 549$ cells following CSE treatments. To determine the effects of CSE on the $\beta$-catenin levels in A549 cells, the $\beta$-catenin protein levels were analyzed by western blot analysis. The results showed that the total, cytosolic and nuclear $\beta$-catenin levels were increased upon exposure to CSE, compared to those in the control cells.
The increases in nuclear $\beta$-catenin were more significant at concentrations of $10-80 \mu \mathrm{g} / \mathrm{ml}$, and total $\beta$-catenin and cytosolic $\beta$-catenin at concentrations of $40-80 \mu \mathrm{g} / \mathrm{ml}$ (all $\mathrm{P}<0.05$ ). In addition, the increases were dose-dependent (Fig. 2). The levels of $\beta$-catenin in the A549 cells exposed to CSE were also examined by immunofluorescence staining. The results showed that strongly positive $\beta$-catenin cells were detected in both the cytoplasm and nuclei of the CSE-treated cells and that the expression was more significant in the nuclei of cells exposed to $40 \mu \mathrm{g} / \mathrm{ml} \mathrm{CSE}$ for $48 \mathrm{~h}$, while the $\beta$-catenin expression was only slightly positive in the control cells (Fig. 3A). To further study the mechanisms, other molecules involved in the $\mathrm{Wnt} / \beta$-catenin/TCF pathway were examined. Compared to the untreated control groups, western blot 


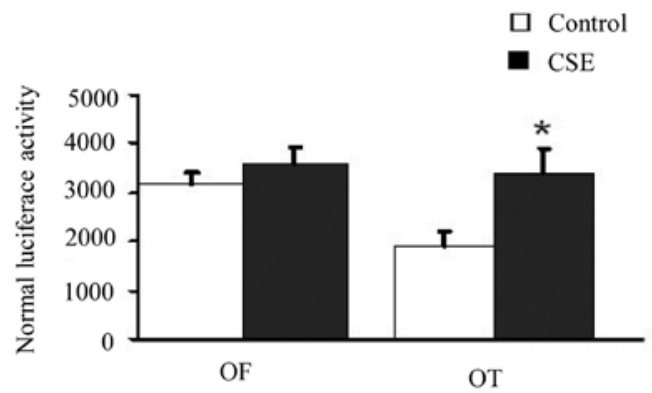

Figure 4. Activation of $\beta$-catenin/TCF signaling in the A549 cells following CSE treatments. The luciferase and $\beta$-galactosidase activities in the A549 cells following CSE treatments were detected using commercial kits according to the manufacturer's instructions. OF indicates cells transfected with pGL3-OF (mutant-type as a control vector). OT indicates cells transfected with pGL3OT (wild-type). The white columns show the control group transfected with the luciferase reporter plasmid (pGL3-OF or pGL3-OT) alone. The black columns show the groups transfected with the luciferase reporter plasmid followed by CSE treatment. The data represent the means \pm standard error from three independent experiments. ${ }^{*} \mathrm{P}<0.05$, indicates comparison between the CSE-treated group and the DMSO-treated control group.

analysis showed that the levels of phosphorylated $\beta$-catenin and total GSK-3 $\beta$ were decreased, while phosphorylated GSK-3 $\beta$, FRB, Wnt2 and Wnt7a were increased following treatment with $40 \mu \mathrm{g} / \mathrm{ml} \mathrm{CSE}$ (Fig. 3B).

Activation of $\beta$-catenin/TCF signaling in the A549 cells following CSE treatments. The luciferase activity assay showed that the luciferase activity in the the CSE-exposed cells transfected with the TCF luciferase reporter wild-type plasmid (pGL3-OT) was significantly greater than that in the cells without CSE exposure $(33,167 \pm 3,085$ vs. $19,978 \pm 1,916$, respectively; $\mathrm{P}<0.05)$. Meanwhile, the luciferase activity in the CSE-exposed cells transfected with the TCF luciferase reporter mutant plasmid (pGL3-OF) was similar to that in the cells without CSE exposure (35,657 $\pm 2,301$ vs. $32,908 \pm 2,350$, respectively, $\mathrm{P}>0.05$ ). These results suggest that the $\beta$-catenin/ TCF signaling pathway was activated in cells following CSE treatment (Fig. 4).

Downregulation of RBM5 in the A549 cells following CSE treatments. To determine the effect of CSE on the RBM5 level in cells, we examined both the mRNA and protein levels of RBM5 in the A549 cells following treatment with various concentrations of CSE at different time-points. The real-time PCR results showed that CSE inhibited the RBM5 mRNA levels in both a dose- and time-dependent manner. The foldchange in gene expression was significantly reduced at 40 and $80 \mu \mathrm{g} / \mathrm{ml}$ at $24 \mathrm{~h}$; at 10, 20, 40 and $80 \mu \mathrm{g} / \mathrm{ml}$ at $48 \mathrm{~h}$; and at 0, 20, 40 and $80 \mu \mathrm{g} / \mathrm{ml}$ at $72 \mathrm{~h}$ (all $\mathrm{P}<0.05$ ) (Fig. 5A and B). In addition, the western blot analysis showed that the RBM5 protein levels were reduced in the cells treated with CSE for $48 \mathrm{~h}$ and that the levels were significantly reduced at 20 and $80 \mu \mathrm{g} / \mathrm{ml}$. The RBM5 expression level after treatment with $40 \mu \mathrm{g} / \mathrm{ml} \mathrm{CSE}$ was slightly greater than that after treatment with $20 \mu \mathrm{g} / \mathrm{ml} \mathrm{CSE}$. These results suggest that CSE inhibited RBM5 protein expression (Fig. 5C and D).

RBM5 regulates Wnt/ $\beta$-catenin signaling in the A549 cells. To determine the effects of RBM5 on Wnt/ $\beta$-catenin signaling in the A549 cells, we either overexpressed wild-type RBM5 or knocked down RBM5 using RBM5 shRNA in the cells. As shown in Fig. 6, compared with the control group,
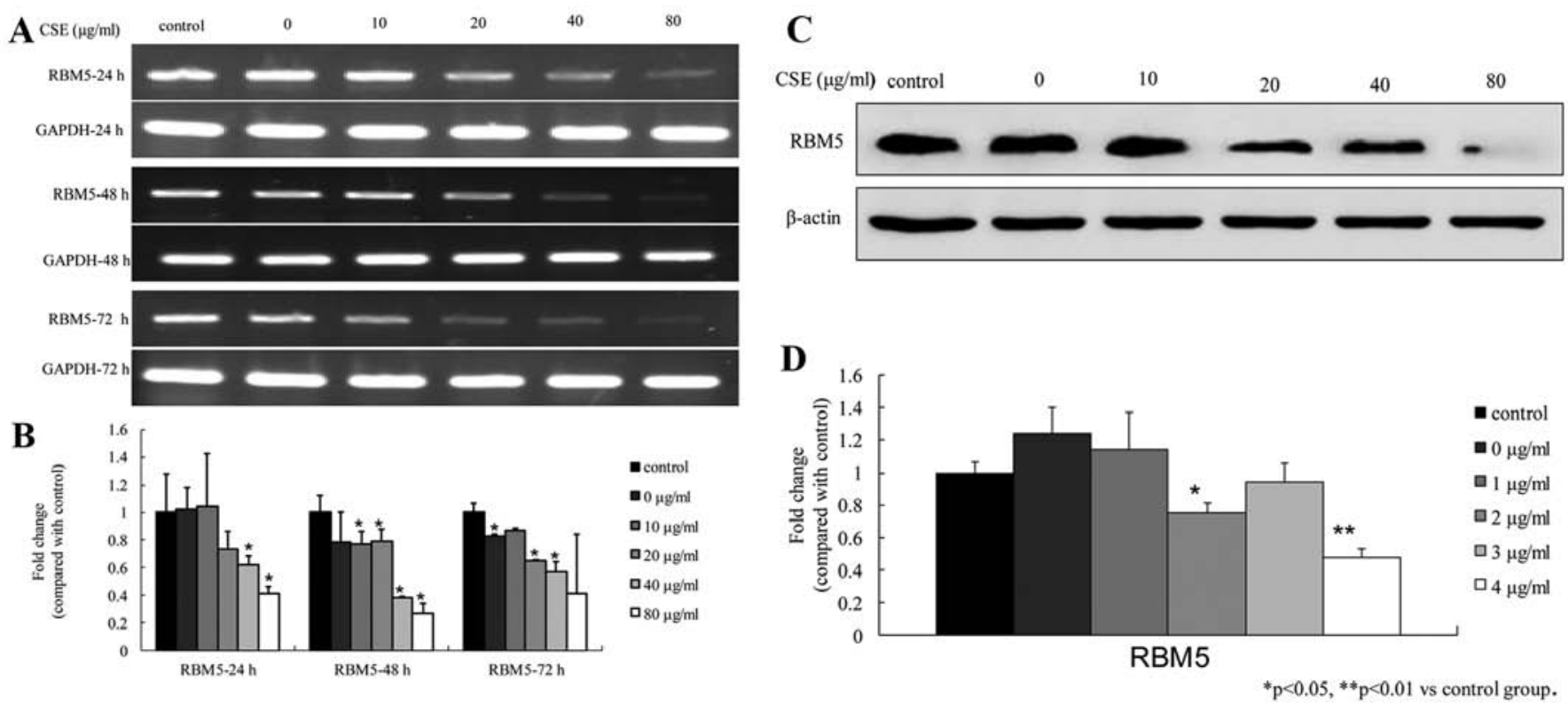

Figure 5. Downregulation of RBM5 in the A549 cells following CSE treatments. The cells were treated with different concentrations of CSE or DMSO for 24 , 48 and 72 h, respectively. (A and B) Total RNA was extracted from the cells following CSE treatments for 24, 48 and 72 h, respectively. The relative mRNA levels of RBM5 in the A549 cells were detected by semi-quantitative RT-PCR. GAPDH was used as an internal reference. (C and D) Whole cell lysates were extracted from the cells following CSE treatment for $48 \mathrm{~h}$. The protein levels in the A549 cells were detected by western blot analysis using anti-RBM5 and anti- $\beta$-actin antibodies. Data represent the mean \pm standard deviation from three replicate experiments. ${ }^{*} \mathrm{P}<0.05,{ }^{* *} \mathrm{P}<0.01$ compared with the DMSO-treated control group. 

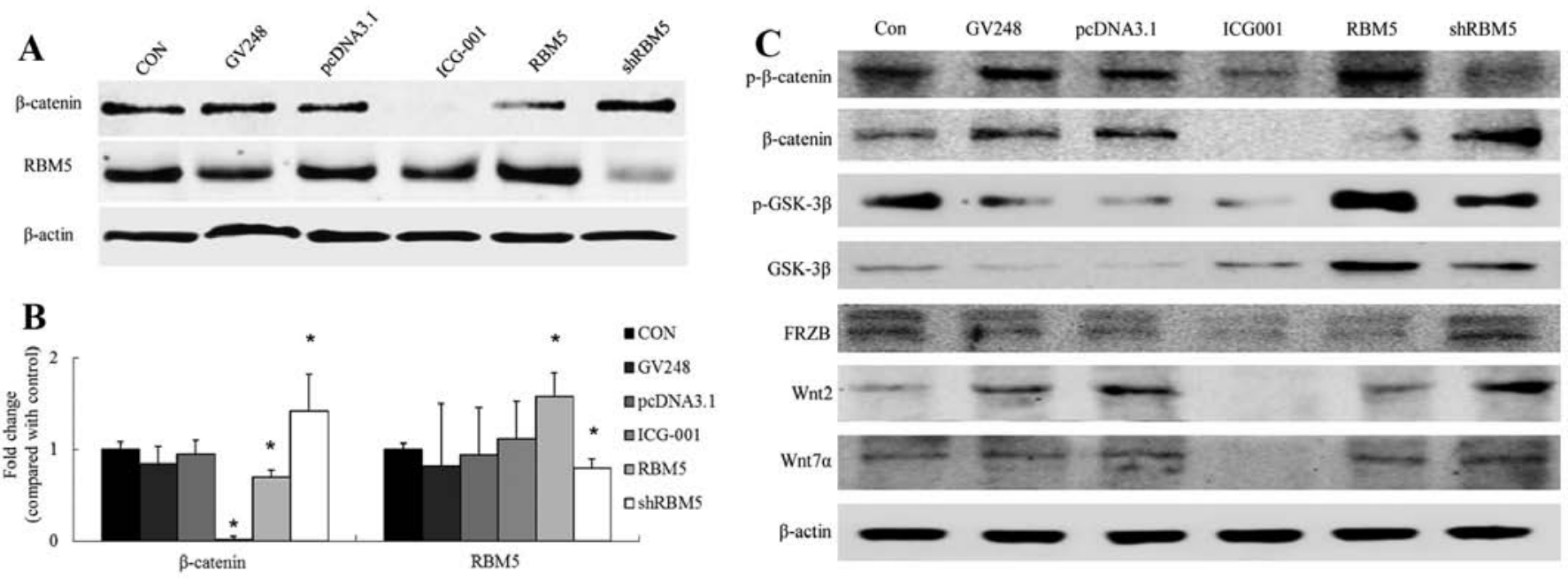

Figure 6. RBM5 regulates $\beta$-catenin expression in the A549 cells following CSE treatments. (A) A549 cells were transfected with pcDNA3-RBM5 (RBM5), GV248-shRBM5 (shRBM5), pcDNA3.1, or GV248 or treated with ICG-001, respectively. Whole cell lysates were extracted from the cells after transfection for $48 \mathrm{~h}$. The cell lysates were subjected to western blot analysis using anti-RBM5, anti- $\beta$-catenin or anti- $\beta$-actin antibodies. $\beta$-actin was used as an internal control. (B) The fold-change in protein levels was expressed as the mean \pm standard deviation from three replicate experiments. "P<0.05 compared with the DMSOtreated control group. (C) Whole cell lysates were extracted, and western blot analysis was performed as described in Materials and methods. Con, control.

overexpression of RBM5 significantly inhibited $\beta$-catenin expression in the A549 cells $(\mathrm{P}<0.05)$, increased phosphorylation of $\beta$-catenin and GSK-3 $\beta$, and increased total GSK-3 $\beta$ expression. In contrast, silencing of RBM5 significantly enhanced the $\beta$-catenin level in the A549 cells $(\mathrm{P}<0.05)$, reduced phosphorylation of $\beta$-catenin and GSK-3 $\beta$ and reduced total GSK-3 $\beta$ expression. Furthermore, the cells were treated with the $\beta$-catenin/TCF signaling inhibitor ICG-001. The data showed that ICG-001 had no apparent effect on the RBM5 expression level in the cells. These studies suggest that RBM5 is an upstream molecule that regulates Wnt/ $\beta$-catenin signaling and negatively regulates this pathway in A549 cells (Fig. 6).

\section{Discussion}

The primary purpose of the present study was to determine whether the RBM5 level is reduced and whether it regulates Wnt/ $\beta$-catenin signaling in cigarette smoke-induced lung injury. The A549 cell line has been considered to be a preferred cellular model for studies related to type II alveolar epithelial cells, which secrete specific type II cell markers including surfactant proteins and some other markers $(17,18)$. In the present study, A549 cells were exposed to various concentrations of CSE for different periods of time. We observed that CSE is cytotoxic to alveolar epithelial cells as it inhibited the viability of cells in a dose- and time-dependent manner. Our study is consistent with previous reports $(19,20)$. Cigarette smoke is a complex mixture of harmful chemicals, some of which are known carcinogens. Recent research has shown that A549 cells are more vulnerable to harmful chemicals in CSE than other types of cells (21).

In the present study, we observed that both cytosolic and nuclear $\beta$-catenin levels in the CSE-treated cells were significantly elevated following CSE exposure for $48 \mathrm{~h}$, compared with those in the control cells. According to the western blot results, there were increased nuclear $\beta$-catenin levels in the cytoplasm as well as increased cytosolic $\beta$-catenin and total $\beta$-catenin levels in the nuclei. These results were also confirmed by an increased number of $\beta$-catenin-positive cells in both the cytoplasm and nuclei as examined by immunofluorescence staining. The changes were dose-dependent. Unfortunately, proteins were only collected from cells treated for $48 \mathrm{~h}$. Thus, we were unable to determine whether the changes were also time-dependent. These findings suggest that CSE upregulates $\beta$-catenin levels and promotes $\beta$-catenin cytosolic accumulation and nuclear translocation. In addition, the luciferase activity assay showed that the luciferase activity in the CSE-exposed cells transfected with the TCF luciferase reporter wild-type plasmid (pGL3-OT) was significantly greater than that in cells without CSE exposure. These results suggest that $\mathrm{Wnt} / \beta$-catenin signaling was activated in the CSE-exposed lung epithelial cells. Previous studies have shown that $\mathrm{Wnt} / \beta$-catenin signaling is activated in lung injury $(5,14,15,22)$. Moreover, aberrant activation of WNT signaling also has been reported in the airway of cigarette smoke-associated COPD (23). Thus, the present study is in line with these reports, confirming that aberrant activation of Wnt/ $\beta$-catenin signaling exists in cigarette smoke-associated airway injury and is responsible for cell proliferation and tissue remodeling at the late stage of injury in response to CSE stimuli. However, one report has contradicted these studies, suggesting that smoking downregulates the $\mathrm{Wnt} / \beta$-catenin pathway in the human airway epithelium and contributes to the dysregulation of airway epithelium differentiation observed in smoking-related airway disorders (24).

Previous studies suggest that frequently reduced RBM5 levels exist in different types of tumors including breast cancer (25), schwannoma (26), and $75 \%$ of primary lung cancers (27). We previously reported that the protein levels of RBM5 are lower in NSCLC compared with non-tumorous tissues (13). In addition, we studied the possible involvement of RBM5 in drug resistance during chemotherapy using a cisplatin-sensitive and a cisplatin-resistant NSCLC cell 
line (10). These studies suggest that RBM5 plays a role in suppressing tumor development and progression. Additionally, the RBM5 level has been shown to be higher in the adult thymus compared with that in the fetal thymus, which suggests that RBM5 may also be involved in normal development (28). Furthermore, the inhibitory effects of RBM5 on tumor growth both in vitro and in vivo have been suggested due to its induction of G1 cell cycle arrest and apoptosis (25). In the present study, for the first time, we observed that both the mRNA and protein levels of RBM5 in the CSE-injured lung epithelium also were significantly reduced compared to the controls. The reductions in human alveolar epithelial cells were both timeand dose-dependent. Similarly, a study from another group showed that a decreased RBM5 level was more frequently observed in the alveolar epithelium of smokers than of nonsmokers (13). Together, these data suggest that loss of RBM5 contributes to cell proliferation and tumor transformation. The possible molecular mechanisms may involve cell cycle arrest and induction of apoptosis.

Given that RBM5 was downregulated and Wnt/ $\beta$-catenin signaling was activated in the CSE-exposed alveolar epithelial cells, we postulated that RBM5 may be involved in the activation of Wnt/ $\beta$-catenin signaling in CSE-induced lung injury. To further study whether RBM5 regulates $\beta$-catenin signaling, we examined the protein level of $\beta$-catenin in the A549 cells following the overexpression of wild-type RBM5 or the silencing of RBM5 using RBM5 shRNA in these cells. The present study revealed that overexpression of RBM5 significantly inhibited Wnt/ $\beta$-catenin signaling in A549 cells, while silencing of RBM5 significantly enhanced Wnt $/ \beta$ catenin signaling in the A549 cells. However, the $\beta$-catenin/ TCF signaling inhibitor ICG-001 had no apparent effect on the RBM5 level in cells. These results suggest that RBM5 acted as an upstream molecule of Wnt/ $\beta$-catenin/TCF signaling and that RBM5 negatively regulates this pathway in A549 cells.

In summary, we demonstrated that CSE leads to epithelial injury by directly inhibiting the viability of alveolar epithelial cells. Downregulation of RBM5 and activation of Wnt/ $\beta$-catenin signaling are involved in CSE-induced alveolar epithelial injury. In addition, RBM5 acts as an upstream molecule that negatively regulates the activity of $\mathrm{Wnt} / \beta$-catenin signaling.

\section{Acknowledgements}

We thank Medjaden Bioscience Limited for assisting in the preparation of this manuscript.

\section{References}

1. Feldman C and Anderson R: Cigarette smoking and mechanisms of susceptibility to infections of the respiratory tract and other organ systems. J Infect 67: 169-184, 2013.

2. Niewoehner DE: Cigarette smoking, lung inflammation, and the development of emphysema. J Lab Clin Med 111: 15-27, 1988.

3. Sangani RG and Ghio AJ: Lung injury after cigarette smoking is particle related. Int J Chron Obstruct Pulmon Dis 6: 191-198, 2011.

4. Ye Q, Huang K, Ding Y, et al: Cigarette smoking contributes to idiopathic pulmonary fibrosis associated with emphysema. Chin Med J (Engl) 127: 469-474, 2014.
5. Flozak AS, Lam AP, Russell S, et al: Beta-catenin/T-cell factor signaling is activated during lung injury and promotes the survival and migration of alveolar epithelial cells. J Biol Chem 285: 3157-3167, 2010.

6. Clevers H: Wnt/beta-catenin signaling in development and disease. Cell 127: 469-480, 2006.

7. Liu F and Millar SE: Wnt/beta-catenin signaling in oral tissue development and disease. J Dent Res 89: 318-330, 2010.

8. He X, Semenov M, Tamai K and Zeng X: LDL receptor-related proteins 5 and 6 in Wnt/beta-catenin signaling: arrows point the way. Development 131: 1663-1677, 2004.

9. Huelsken $J$ and Birchmeier W: New aspects of Wnt signaling pathways in higher vertebrates. Curr Opin Genet Dev 11: 547-553, 2001.

10. Li P, Wang K, Zhang J, et al: The 3p21.3 tumor suppressor RBM5 resensitizes cisplatin-resistant human non-small cell lung cancer cells to cisplatin. Cancer Epidemiol 36: 481-489, 2012.

11. Oh JJ, Taschereau EO, Koegel AK, et al: RBM5/H37 tumor suppressor, located at the lung cancer hot spot 3p21.3, alters expression of genes involved in metastasis. Lung Cancer 70: 253-262, 2010.

12. Sutherland LC, Wang K and Robinson AG: RBM5 as a putative tumor suppressor gene for lung cancer. J Thorac Oncol 5: 294-298, 2010

13. Liang H, Zhang J, Shao C, et al: Differential expression of RBM5, EGFR and KRAS mRNA and protein in non-small cell lung cancer tissues. J Exp Clin Cancer Res 31: 36, 2012.

14. Lemjabbar-Alaoui H, Dasari V, Sidhu SS, et al: Wnt and Hedgehog are critical mediators of cigarette smoke-induced lung cancer. PLoS One 1: e93, 2006.

15. Tian D, Zhu M, Li J, Ma Y and Wu R: Cigarette smoke extract induces activation of beta-catenin/TCF signaling through inhibiting GSK3beta in human alveolar epithelial cell line. Toxicol Lett 187: 58-62, 2009.

16. Zhang X, Xiao T, Cheng S, Tong T and Gao Y: Cigarette smoke suppresses the ubiquitin-dependent degradation of OLC1. Biochem Biophys Res Commun 407: 753-757, 2011.

17. Andreeva AV, Kutuzov MA and Voyno-Yasenetskaya TA: Regulation of surfactant secretion in alveolar type II cells. Am J Physiol Lung Cell Mol Physiol 293: L259-L271, 2007.

18. Fehrenbach H: Alveolar epithelial type II cell: defender of the alveolus revisited. Respir Res 2: 33-46, 2001.

19. Hoshino Y, Mio T, Nagai S, Miki H, Ito I and Izumi T: Cytotoxic effects of cigarette smoke extract on an alveolar type II cellderived cell line. Am J Physiol Lung Cell Mol Physiol 281: L509-L516, 2001.

20. Lannan S, Donaldson K, Brown D and MacNee W: Effect of cigarette smoke and its condensates on alveolar epithelial cell injury in vitro. Am J Physiol 266: L92-L100, 1994.

21. Cavallo D, Ursini CL, Fresegna AM, et al: Cyto-genotoxic effects of smoke from commercial filter and non-filter cigarettes on human bronchial and pulmonary cells. Mutat Res 750: 1-11, 2013.

22. Pongracz JE and Stockley RA: Wnt signalling in lung development and diseases. Respir Res 7: 15, 2006.

23. Heijink IH, de Bruin HG, van den Berge M, et al: Role of aberrant WNT signalling in the airway epithelial response to cigarette smoke in chronic obstructive pulmonary disease. Thorax 68: 709-716, 2013.

24. Wang R, Ahmed J, Wang G, et al: Down-regulation of the canonical Wnt beta-catenin pathway in the airway epithelium of healthy smokers and smokers with COPD. PLoS One 6: e14793, 2011.

25. Edamatsu H, Kaziro Y and Itoh H: LUCA15, a putative tumour suppressor gene encoding an RNA-binding nuclear protein, is down-regulated in ras-transformed Rat-1 cells. Genes Cells 5: 849-858, 2000.

26. Welling DB, Lasak JM, Akhmametyeva E, Ghaheri B and Chang LS: cDNA microarray analysis of vestibular schwannomas. Otol Neurotol 23: 736-748, 2002.

27. Oh JJ, West AR, Fishbein MC and Slamon DJ: A candidate tumor suppressor gene, H37, from the human lung cancer tumor suppressor locus 3p21.3. Cancer Res 62: 3207-3213, 2002.

28. Ji L, Minna JD and Roth JA: 3p21.3 tumor suppressor cluster: prospects for translational applications. Future Oncol 1: 79-92, 2005. 